\begin{tabular}{c} 
International Journal of Engineering \& Technology, $7(3)(2018) 1272-1275$ \\
Snternational Journal of Engineering \& Technology \\
SPC \\
Website: $\begin{array}{c}\text { ww. sciencepubco.com/index.php/IJET } \\
\text { doi: } 10.14419 / \text { ijet.v7i3.11333 } \\
\text { Research paper }\end{array}$ \\
\hline
\end{tabular}

\title{
Effect of matrix size in affecting noise reduction level of filtering
}

\author{
Khairul $^{1}$, Rian Farta Wijaya ${ }^{1}$, Andysah Putera Utama Siahaan ${ }^{1,5}$, , Solly Aryza ${ }^{1,5}$, Fitria Nova Hulu ${ }^{1}$, \\ Rusiadi $^{2}$, Henry Aspan ${ }^{2}$, Muhammad Dharma Tuah Putra Nasution ${ }^{2}$, Yossie Rossanty ${ }^{2}$, \\ Darmawan Napitupulu ${ }^{3}$, Diki Arisandi ${ }^{4}$ \\ ${ }^{1}$ Faculty of Science and Technology, Universitas Pembangunan Panca Budi, Medan, Indonesia \\ ${ }^{2}$ Faculty of Social Science, Universitas Pembangunan Panca Budi, Medan, Indonesia \\ ${ }^{3}$ Research Center for Quality System and Testing Technology, Indonesian Institute of Sciences \\ ${ }^{4}$ Faculty of Engineering, Department of Informatics, Universities Abdurrab, Pekanbaru, Indonesia \\ ${ }^{5}$ Postgraduate Student of School of Computer and Communication Engineering, Universiti Malaysia Perlis, Pauh, Malaysia \\ *Corresponding author E-mail:andiesiahaan@gmail.com
}

\begin{abstract}
Improved image quality needs to be done to improve data processing on the image. This quality improvement can be made by doing masking technique. Median Filter is one technique to enhance the quality of an image in a particular space. Median filtering improves the image by specifying a specific pixel from its neighboring pixels. The median filtering calculation uses a matrix block with an odd number. Each matrix block will have a middle value after the pixel values have regularly been sorted. This method is included in the category of nonlinear filtering. With the median filtering, the output pixel value is determined by the median of the specified mask environment. Median Filter has different results when using different matrix sizes as well. The results of this process can determine how gentle the result of noise reduction. In general, the larger the size of the matrix, the higher the blurriness of an image.
\end{abstract}

Keywords: Image Processing; Median Filter; Matrix Size

\section{Introduction}

Information is a precious data delivered through the power grid. [1] [2]. Without the presence of electricity, the computer can not display the image. Information retrieval is the most important thing [3]-[11] An image can save the beauty of a moment, giving and hiding valuable information [12]-[14]. Image smoothing is a step to reduce noise on an image. It can be done with a median filter. The smoothing process is done by determining the pixel statistics that are in the neighborhood area [15]-[17] Any potentially changing pixels will be replaced with the median value of the pixel value set that exists in the window of this neighborhood after ordering. The median filter is used to create a softer image than the original. For example, photos were taken at night often experience noise [18]. Noise is the value that appears most rarely in an image [19] [20]. It causes the median filter to work on the original image that has variations in the color intensity that tend to be homogeneous. This technique can be combined using other statistics. The noise can be reduced so that the photo looks cleaner than the original [21]. The median filter has a unit of measure to determine the degree of blurring [22]. It is expressed by the size of the matrix on each test block. The resulting object has different noise reduction levels. The matrix used is odd. In this study will be tested several sizes, $3 \times 3,5 \times 5$, and $7 \times 7$. Each matrix will have a significant difference to the others. Specifying the size of the matrix will allow the user to choose the best image. Each size has different speeds. The median filter image can be used for extracting features and other processes.

\section{Theories}

\subsection{Noise reduction}

Images are visualizations of an activity. Each image has three color layers [23]-[26] Noise on an image can occur due to gray-level characteristics or random variables that occur due to the characteristics of the Probability Density Function. If the image containing the noise is directly processed and extracted, then its important features can cause accuracy problems [27]-[29] So it should be cleaned out of noise first, and then processed to extract its important features. The technique for reducing noise is orderstatistics filters, which are spatial filters where the response results are based on the sorting of pixel values enclosed by filters [30].

\subsection{Median filtering}

Image quality is the selling value that makes money when viewed from economic factors [31]. Median filtering is the most known order-statistic filter. The workings of these filters are formulated in the following equations:

$$
\mathrm{F}(\mathrm{x}, \mathrm{y})=\operatorname{Median}(\mathrm{s}, \mathrm{t}) € \operatorname{sxy}\{\mathrm{g}(\mathrm{s}, \mathrm{t})\}
$$

The median filtering takes a certain area of the image according to the size of the specified mask [32], then views each pixel value in that area, and the value of the area in the change with the median value [33] [34]. The method of obtaining the median value is: the 
gray value of the points on the matrix is sorted from the smallest to the largest, then in the middle value of the pixel series [27].

For certain types of noise, this filter provides excellent reducing capacity, with less blurring than a linear smoothing filter for the same image size [35]-[37] Median filtering offers excellent results for images exposed to bipolar and unipolar impulse noise [38]. Examples of noise reduction results using median filtering can be seen in the following figure [39].
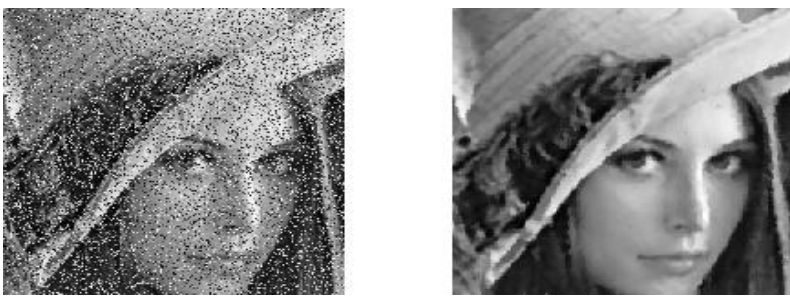

Fig. 1: (A) Noisy Image (B) Median Filtering Image.

Figure 1 (a) explains that the image contains noise in the form of grayish white spots that disturb the eye. These spots are created because the quality of the camera is less suitable for a low light condition. The result of median filter improvement can be seen in Figure 1 (b) where the grayish white spots have faded or disappeared and are disguised based on the neighboring pixels depending on the size of the matrix used [40].

\section{Methodology}

\subsection{Median filtering $3 \times 3$}

Median filtering uses a matrix to perform calculations of replacement pixel values. The calculation below has a $3 \times 3$ matrix size. The initial image given is a $10 \times 10$ pixel size as shown in the following table.

Table 1: Initial Pixel Data

\begin{tabular}{llllllllll}
\hline 164 & 187 & 181 & 217 & 129 & 156 & 234 & 172 & 44 & 143 \\
\hline 102 & 10 & 208 & 180 & 9 & 97 & 253 & 75 & 234 & 126 \\
75 & 202 & 2 & 210 & 59 & 82 & 144 & 24 & 5 & 68 \\
179 & 164 & 32 & 16 & 167 & 217 & 20 & 14 & 16 & 42 \\
227 & 170 & 123 & 171 & 167 & 58 & 114 & 188 & 220 & 16 \\
93 & 218 & 190 & 97 & 102 & 172 & 210 & 212 & 168 & 243 \\
158 & 50 & 28 & 108 & 221 & 38 & 33 & 195 & 253 & 176 \\
0 & 87 & 226 & 219 & 39 & 148 & 163 & 63 & 84 & 17 \\
168 & 125 & 191 & 57 & 42 & 45 & 33 & 38 & 230 & 132 \\
241 & 130 & 190 & 145 & 211 & 244 & 22 & 100 & 141 & 231 \\
63 & 176 & 25 & 138 & 82 & 192 & 126 & 177 & 32 & 113 \\
\hline
\end{tabular}

Table 1 describes the pixel value of the original image. The first stage is to take as much as 9 pixels from the upper left corner of the image. Image snippets can be seen as follows:

\begin{tabular}{lll}
\hline 164 & 187 & 181 \\
\hline 102 & 10 & 208 \\
75 & 202 & 2 \\
\hline
\end{tabular}

The pixel values are exposed in a one-dimensional vector. The value of the pixel is sorted first from small to large to produce as below.

\begin{tabular}{lllllllll}
\hline 2 & 10 & 75 & 102 & 164 & 181 & 187 & 202 & 208 \\
\hline
\end{tabular}

The median value is 164 . It is located in the fifth column. The pixel in the middle of $3 \times 3$ matrix will be replaced by the median value. The value " 10 " is replaced by " 164 ". The new pixel formation is shown in the following block.

\begin{tabular}{lll}
\hline 164 & 187 & 181 \\
\hline 102 & 164 & 208 \\
75 & 202 & 2 \\
\hline
\end{tabular}

\subsection{Median filtering $5 \times 5$}

The median filtering calculation on the $5 \times 5$ matrix is the same as the $3 \times 3$ matrix. The fundamental difference is the number of neighboring pixels to be compared. The illustration below describes the calculation. The pixel data table used is the same as before. The pixel block will be loaded 25 pixels consisting of five columns and five rows as shown below.

\begin{tabular}{lllll}
\hline 164 & 187 & 181 & 217 & 129 \\
\hline 102 & 10 & 208 & 180 & 9 \\
75 & 202 & 2 & 210 & 59 \\
179 & 164 & 32 & 16 & 167 \\
227 & 170 & 123 & 171 & 167 \\
\hline
\end{tabular}

The pixel values are exposed in a one-dimensional vector as well. The value of the pixel is sorted first from small to large to produce as below.

\begin{tabular}{lllll}
\hline 2 & 9 & 10 & 16 & 32 \\
\hline 59 & 75 & 102 & 123 & 129 \\
164 & 164 & 167 & 167 & 170 \\
171 & 179 & 180 & 181 & 187 \\
202 & 208 & 210 & 217 & 227 \\
\hline
\end{tabular}

The median value is 167 . It is located column 13. The pixel in the middle of $5 \times 5$ matrix will be replaced by the median value. The value " 2 " is replaced by " 167 ". The new pixel formation is shown in the following block.

\begin{tabular}{lllll}
\hline 164 & 187 & 181 & 217 & 129 \\
\hline 102 & 10 & 208 & 180 & 9 \\
75 & 202 & 167 & 210 & 59 \\
179 & 164 & 32 & 16 & 167 \\
227 & 170 & 123 & 171 & 167 \\
\hline
\end{tabular}

\subsection{Median filtering $7 \times 7$}

The median filtering calculation on the $7 \times 7$ matrix takes 49 pixels. The illustration below describes the calculation. The pixel data table used is the same as before. The pixel block will be loaded consisting of seven columns and seven rows as shown below.

\begin{tabular}{lllllll}
\hline 164 & 187 & 181 & 217 & 129 & 156 & 234 \\
\hline 102 & 10 & 208 & 180 & 9 & 97 & 253 \\
75 & 202 & 2 & 210 & 59 & 82 & 144 \\
179 & 164 & 32 & 16 & 167 & 217 & 20 \\
227 & 170 & 123 & 171 & 167 & 58 & 114 \\
93 & 218 & 190 & 97 & 102 & 172 & 210 \\
158 & 50 & 28 & 108 & 221 & 38 & 33 \\
\hline
\end{tabular}

The pixel values are exposed in a one-dimensional vector as well. The value of the pixel is sorted first from small to large to produce as below.

\begin{tabular}{lllllll}
\hline 2 & 9 & 10 & 16 & 20 & 28 & 32 \\
\hline 33 & 38 & 50 & 58 & 59 & 75 & 82 \\
93 & 97 & 97 & 102 & 102 & 108 & 114 \\
123 & 129 & 144 & 156 & 158 & 164 & 164 \\
167 & 167 & 170 & 171 & 172 & 179 & 180 \\
181 & 187 & 190 & 202 & 208 & 210 & 210 \\
217 & 217 & 218 & 221 & 227 & 234 & 253 \\
\hline
\end{tabular}

The median value is 156 . It is located column 25 . The pixel in the middle of $7 \times 7$ matrix will be replaced by the median value. The value " 16 " is replaced by " 156 ". The new pixel formation is shown in the following block.

\begin{tabular}{lllllll}
\hline 164 & 187 & 181 & 217 & 129 & 156 & 234 \\
\hline 102 & 10 & 208 & 180 & 9 & 97 & 253 \\
75 & 202 & 2 & 210 & 59 & 82 & 144 \\
179 & 164 & 32 & 156 & 167 & 217 & 20 \\
227 & 170 & 123 & 171 & 167 & 58 & 114 \\
\hline
\end{tabular}




\begin{tabular}{lllllll}
\hline 93 & 218 & 190 & 97 & 102 & 172 & 210 \\
158 & 50 & 28 & 108 & 221 & 38 & 33 \\
\hline
\end{tabular}

\section{Result and discussion}

\subsection{Good quality image test}

This section tests the noisy image. The median filtering results in the image will be compared against other imagery. The image will have a variation in the degree of blurring. The first test takes an image of $600 \times 600$ pixels.
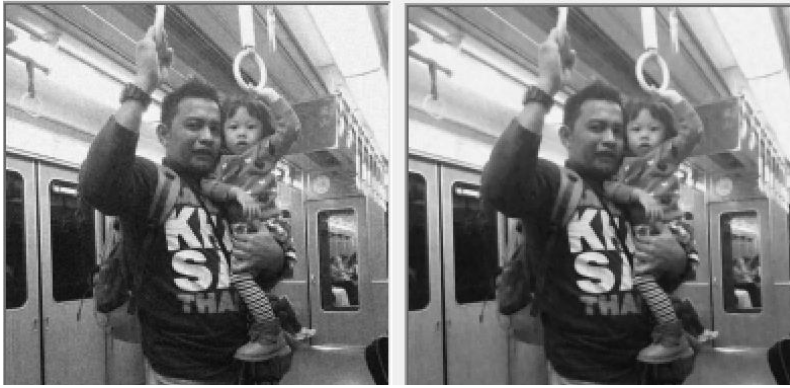

Fig. 2: 3 X 3 Median Filtering (600 X 600 Pixels)

Figure 2 illustrates an image using a $3 \times 3$ matrix size as a median filtering process. There is no significant result to these two images because of the small size of the matrix. The median filter process at this size has pretty good speed.
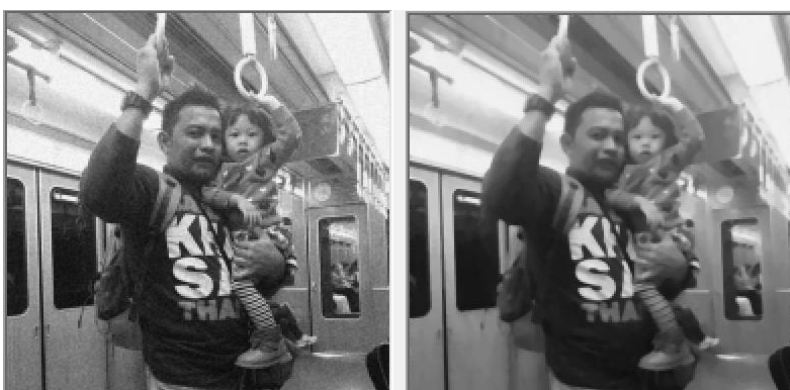

Fig. 3: 5 X 5 Median Filtering (600 X 600 Pixels).

The image resulted in Figure 3 has started to blur a bit. The sharpness of the image is deficient due to the smoothing of the resulting image by using the $5 \times 5$ matrix. This measure shows good median values. Noise on the original image will decrease if this process is done.
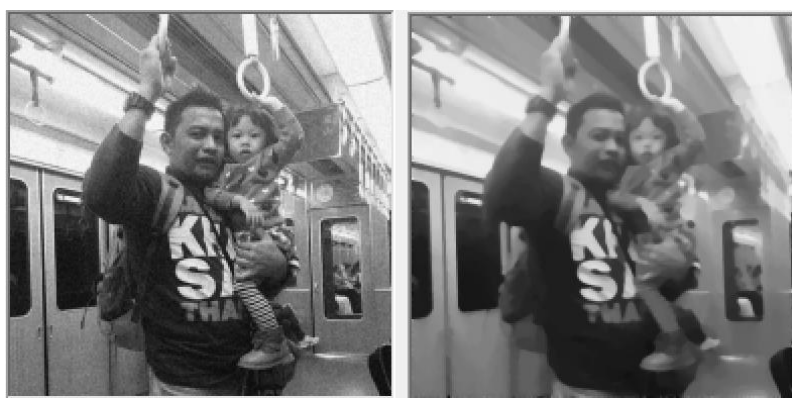

Fig. 4: 7 X 7 Median Filtering (600 X 600 Pixels).

The use of the $7 \times 7$ matrix in Figure 4 affects the image results significantly. The original image and the image of the median filter feels so different. It happens because the size of this matrix compares 49 pixels so that there are parts that will become blurred due to the effect of median filter usage.

\subsection{Low resolution image test}

The second test tests the image with low quality. The image tested is a $130 \times 100$ pixel image.
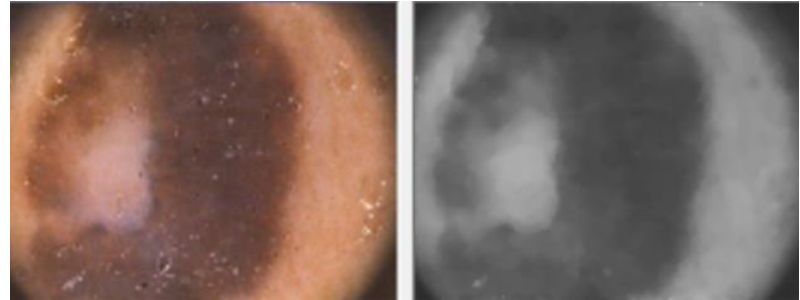

Fig. 5: 3 X 3 Median Filtering (130 X 100 Pixels).

In the low-resolution test, the use of $3 \times 3$ matrix size can display significant results. Figure 5 illustrates some white noise; this noise has been terminated on the median filter results.
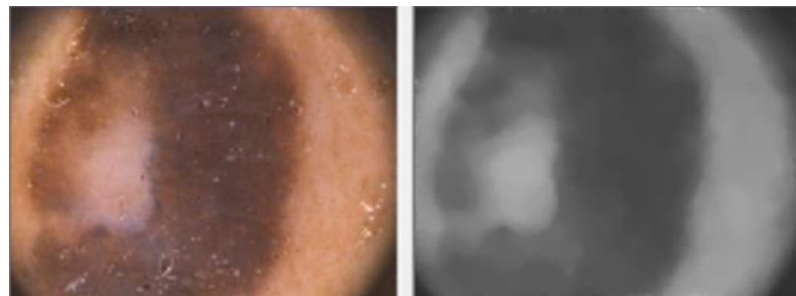

Fig. 6: 5 X 5 Median Filtering (130 X 100 Pixels).

Figure 6 has similar results to figure 5 , but in this image, the image blur of the median filter is higher. Sharp shapes produce more curved and blurred lines.
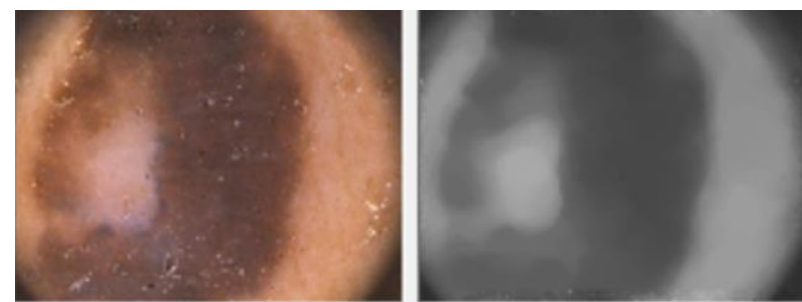

Fig. 7: 7 X 7 Median Filtering (130 X 100 Pixels).

Figure 7 has a very high degree of vagueness. The $7 \times 7$ matrix size will have different results if applied to different resolutions. In lowresolution, the use of this size will change the image like a cartoon image. From previous experiments, it can be seen that the higher the number of matrices, the higher the blur of the image.

\section{Conclusion}

Median filtering is an excellent method to reduce the noise level in an image. Examining neighboring patterns by calculating the mean of the pixels will help mask the noise gaps in the image. The larger the masking space on the median filtering, the higher the blurred image level. The weakness of the median filtering lies in the small image size. Implementing this method on a small image will undermine the authenticity of the image.

\section{References}

[1] S. Aryza, M. Irwanto, Z. Lubis, A. P. U. Siahaan, R. Rahim, and M. Furqan, "A Novelty Design of Minimization of Electrical Losses in A Vector Controlled Induction Machine Drive," in IOP Conference Series: Materials Science and Engineering, 2018, vol. 300, no. 1. https://doi.org/10.1088/1757-899X/300/1/012067.

[2] A. P. U. Siahaan, How to Code: Advanced Encryption Standard in C\#. Medan: Fakultas Ekonomi Universitas Panca Budi, 2018.

[3] A. P. U. Siahaan et al., "Combination of Levenshtein Distance and Rabin-Karp to Improve the Accuracy of Document Equivalence Level,’ Int. J. Eng. Technol., vol. 7, no. 2.27, pp. 17-21, 2018.

[4] A. P. U. Siahaan, "A Fingerprint Pattern Approach to Hill Cipher Implementation."

[5] L. Marlina, Muslim, and A. P. U. Siahaan, "Data Mining Classification Comparison (Naïve Bayes and C4.5 Algorithms)," 
Inte rnational J. Eng. Trends Technol., vol. 38, no. 7, pp. 380-383, 2016. https://doi.org/10.14445/22315381/IJETT-V38P268.

[6] Z. Ramadhan and A. P. U. Siahaan, "Dining Philosophers Theory and Concept in Operating System Scheduling," IOSR J. Comput. Eng., vol. 18, no. 6, pp. 45-50, 2016.

[7] D. Kurnia, H. Dafitri, and A. P. U. Siahaan, "RSA 32-bit Implementation Technique,” Int. J. Recent Trends Eng. Res., vol. 3, $\begin{array}{llll}\text { no. } & 7, & \text { pp. } & 279-284,\end{array}$ https://doi.org/10.23883/IJRTER.2017.3359.UXAIW.

[8] S. Hartanto, M. Furqan, A. P. U. Siahaan, and W. Fitriani, "Haversine Method in Looking for the Nearest Masjid," Int. J. Recent Trends Eng. Res., vol. 3, no. 8, pp. 187-195, Aug. 2017 https://doi.org/10.23883/IJRTER.2017.3402.PD61H

[9] H. M. Ritonga, A. P. U. Siahaan, and Suginam, "Marketing Strategy through Markov Optimization to Predict Sales on Specific Periods," Int. J. Innov. Res. Multidiscip. F., vol. 3, no. 8, pp. 184-190, 2017.

[10] I. Sumartono, A. P. U. Siahaan, and Arpan, "Base64 Character Encoding and Decoding Modeling," Int. J. Recent Trends Eng. Res. vol. 2, no. 12, pp. 63-68, 2016.

[11] W. Fitriani, R. Rahim, B. Oktaviana, and A. P. U. Siahaan, "Vernam Encypted Text in End of File Hiding Steganography Technique," Int. J. Recent Trends Eng. Res., vol. 3, no. 7, pp. 214-219, Jul. 2017. https://doi.org/10.23883/IJRTER.2017.3351.6ON8H

[12] W. Fitriani and A. P. U. Siahaan, "Comparison Between WEKA and Salford System in Data Mining Software," Int. J. Mob. Comput. Appl., vol. 3, no. 4, pp. 1-4, 2016.

[13] A. P. U. Siahaan and R. Rahim, "Dynamic Key Matrix of Hill Cipher Using Genetic Algorithm," Int. J. Secur. Its Appl., vol. 10, no. 8, pp. 173-180, Aug. 2016.

[14] A. P. U. Siahaan, "Adler-32 Integrity Validation in 24bit Color Image."

[15] Supiyandi, M. I. Perangin-angin, A. H. Lubis, A. Ikhwan, Mesran, and A. P. U. Siahaan, "Association Rules Analysis on FP-Growth Method in Predicting Sales," Int. J. Recent Trends Eng. Res., vol. 3 , no. $10, \quad$ pp. $58-65, \quad 2017$ https://doi.org/10.23883/IJRTER.2017.3453.DHCOA.

[16] Pei-Eng Ng and Kai-Kuang Ma, "A Switching Median Filter with Boundary Discriminative Noise Detection for Extremely Corrupted Images,” IEEE Trans. Image Process., vol. 15, no. 6, pp. 1506-1516, Jun. 2006. https://doi.org/10.1109/TIP.2005.871129.

[17] G. Devarajan, V. K. Aatre, and C. S. Sridhar, "Analysis of median filter," in ACE '90. Proceedings of [XVI Annual Convention and Exhibition of the IEEE In India], pp. 274-276. https://doi.org/10.1109/ACE.1990.762694.

[18] M. Saragih, H. Aspan, and A. P. U. Siahaan, "Violations of Cybercrime and the Strength of Jurisdiction in Indonesia," Int. J. Humanit. Soc. Stud., vol. 5, no. 12, pp. 209-214, 2017.

[19] R. Rahim et al., "Combination Base64 Algorithm and EOF Technique for Steganography," J. Phys. Conf. Ser., vol. 1007, no. 1, pp. 1-5, 2018. https://doi.org/10.1088/1742-6596/1007/1/012003.

[20] R. Rahim et al., "Searching Process with Raita Algorithm and its Application," J. Phys. Conf. Ser., vol. 1007, no. 1, pp. 1-7, 2018 https://doi.org/10.1088/1742-6596/1007/1/012004.

[21] A. P. U. Siahaan, "RC4 Technique in Visual Cryptography RGB Image Encryption."

[22] S. Zhang, X. Li, and C. Zhang, "Modified Adaptive Median Filtering," in 2018 International Conference on Intelligent Transportation, Big Data \& Smart City (ICITBS), 2018, pp. 262265. https://doi.org/10.1109/ICITBS.2018.00074.

[23] A. P. U. Siahaan, "A Three-Layer Visual Hash Function Using Adler-32,” Int. J. Comput. Sci. Softw. Eng., vol. 5, no. 7, pp. 142147, 2016.

[24] M. Dharma Tuah Putra Nasution et al., "Decision Support Rating System with Analytical Hierarchy Process Method,” Int. J. Eng. Technol., vol. 7, no. 2.3, pp. 105-108, Mar. 2018.

[25] Y. Rossanty, D. Hasibuan, J. Napitupulu, M. D. T. P. Nasution, and R. Rahim, "Composite performance index as decision support method for multi case problem,” Int. J. Eng. Technol., vol. 7, no. 2.29 , pp. 33-36, 2018

[26] M. D. T. P. Nasution and Y. Rossanty, "Country of Origin as a Moderator of Halal Label and Purchase Behavior," J. Bus. Retail Manag. Res., vol. 12, no. 2, pp. 194-201, 2018 https://doi.org/10.24052/JBRMR/V12IS02/COOAAMOHLAPB.

[27] A. Ikhwan and R. Rahim, "Implementation of Modified Median Filtering Algorithm for Salt \& Pepper Noise Reduction on Image," Int. J. Sci. Technoledge, vol. 4, no. 11, pp. 75-79, 2016.

[28] D. Apdilah, M. Y. Simargolang, and R. Rahim, "A Study of FreiChen Approach for Edge Detection,” Int. J. Sientific Res. Sci. Eng. Technol., vol. 3, no. 1, pp. 59-62, 2017.
[29] F. Russo "Performance Evaluation of Noise Reduction Filters for Color Images through Normalized Color Difference (NCD) Decomposition,” ISRN Mach. Vis., vol. 2014, pp. 1-11, 2014. https://doi.org/10.1155/2014/579658.

[30] R. Meiyanti, A. Subandi, N. Fuqara, M. A. Budiman, and A. P. U. Siahaan, "The Recognition of Female Voice Based on Voice Registers in Singing Techniques in Real-Time using Hankel Transform Method and Macdonald Function,” J. Phys. Conf. Ser., vol. 978, no. 1, pp. 1-6, 2018. https://doi.org/10.1088/1742$\underline{6596 / 978 / 1 / 012051}$

[31] R. Rusiadi, A. Novalina, P. Khairani, and A. P. Utama Siahaan, "Indonesia Macro Economy Stability Pattern Prediction (MundellFlamming Model)," IOSR J. Econ. Financ., vol. 07, no. 05, pp. 1623, May 2016. https://doi.org/10.9790/5933-0705021623.

[32] M. Iqbal, A. P. U. Siahaan, N. E. Purba, and D. Purwanto, "Prim's Algorithm for Optimizing Fiber Optic Trajectory Planning," Int. J. Sci. Res. Sci. Technol., vol. 3, no. 6, pp. 504-509, 2017.

[33] D. Phillips, Image Processing in C,. Kansas: R \& D Publications, 2000

[34] Harmayani and R. Rahim, "24 Bit Image Noise Reduction with Median Filtering Algorithm," Int. J. Recent Trends Eng. Res., vol. 3 , no. $2, \quad$ pp. $\quad 1-5, \quad 2017$. https://doi.org/10.23883/IJRTER.2017.2995.WMEGL.

[35] How-Lung Eng and Kai-Kuang Ma, "Noise Adaptive Softswitching Median Filter," IEEE Trans. Image Process., vol. 10, no. 2, pp. 242-251, 2001. https://doi.org/10.1109/83.902289.

[36] A. R. Rostam pour and A. P. Reeves, "2D median filtering and pseudo median filtering," in [1988] Proceedings. The Twentieth Southeastern Symposium on System Theory, pp. 554-557. https://doi.org/10.1109/SSST.1988.17112.

[37] H. Gómez-Moreno, P. Gil-Jiménez, S. Lafuente-Arroyo, R. LópezSastre, and S. Maldonado-Bascón, "A 'Salt and Pepper' Noise Reduction Scheme for Digital Images Based on Support Vector Machines Classification and Regression," Sci. World J., vol. 2014, pp. 1-15, 2014. https://doi.org/10.1155/2014/826405.

[38] V. V. Khryashchev, A. L. Priorov, I. V. Apalkov, and P. S. Zvonarev, "Image Denoising using Adaptive Switching Median Filter," in IEEE International Conference on Image Processing 2005, 2005, p. I-117. https://doi.org/10.1109/ICIP.2005.1529701.

[39] X. Dong, "Median Filter in AWK," 2015. [Online]. Available: http://onetipperday.sterding.com/2015/06/median-filter-inawk.html. [Accessed: 07-Jun-2018].

[40] B. Merchant, "Lenna, the First Lady of the Internet," Motherboard, 2012. [Online]. Available: https://motherboard.vice.com/en_us/article/z44qg5/meet-lenna-thefirst-lady-of-the-internet-- 2 . 